\title{
O conceito de autonomia em Puig e Jaguaribe: uma análise comparativa intertextual
}

\section{The concept of autonomy in Puig and Jaguaribe: an intertextual comparative analysis}

DOI: $10.21530 /$ ci.v11n2.2016.338

Luciano da Rosa Muñoz ${ }^{1}$

\section{Resumo}

Este artigo pretende analisar e comparar o conceito de autonomia tal como se apresenta em dois textos diferentes: O nacionalismo na atualidade brasileira (1958), de Helio Jaguaribe, e La política exterior argentina: incongruencia epidérmica y coherencia estructural (1982), de Juan Carlos Puig. Em primeiro lugar, será indispensável prover o leitor com seus respectivos contextos de publicação, bem como salientar os objetivos políticos e as fidelidades de grupo de cada autor. Na primeira seção, afirmamos como suas táticas textuais mantêm similitudes no que se refere ao modo como ambos os autores contrastam autonomia e dependência e almejam que o processo de autonomização de seus países emule a bem-sucedida experiência histórica norte-americana. Na sequência, tentamos demonstrar que esses textos diferem em seus entendimentos do que a Terceira Posição deva ser, e ademais apoiam escopos opostos para a integração da América Latina. Finalmente, relacionamos as agendas políticas específicas de cada autor com suas interpretações enviesadas da história da política exterior de seus países.

Palavras-chave: autonomia; história conceitual; intertextualidade; política exterior; relações internacionais.

\begin{abstract}
This paper intends to analyse and compare the concept of autonomy as it is presented in two different texts: Helio Jaguaribe's O nacionalismo na atualidade brasileira (1958) and Juan Carlos Puig's La política exterior argentina: incongruencia epidérmica y coherencia estructural

1 Doutorando e Mestre em Relações Internacionais pela Universidade de Brasília (UnB). Professor de Relações Internacionais no Centro Universitário de Brasília (UniCeub) e de História na União Pioneira de Integração Social (UPIS).

Artigo recebido em 29/02/2016 e aprovado em 03/06/2016.
\end{abstract}


(1982). First of all, it will be indispensable to provide the reader with its respective contexts of publication as well as to stress each author's political goals and group allegiances. In the first section, we affirm how their textual tactics hold similarities with respect to the way both authors contrast autonomy and dependency and hope their countries' process of autonomization emulates the successful American historical experience. Afterwards, we try to demonstrate that those texts differ in their understandings of what the Third Position should be like, and support opposite scopes for the integration of Latin America. Finally, we relate each author's specific political agendas to their one-sided interpretations of their countries' history of foreign policy.

Keywords: autonomy; conceptual history; intertextuality; foreign policy; international relations.

\section{Introdução}

Em seu didático texto sobre o método comparativo, afirma Sartori (1994, p. 37) que comparar implica assimilar e diferenciar. Assim, não poderia haver comparação de duas entidades que em tudo fossem iguais, pois já seriam a mesma coisa. Inversamente, se tais entidades discrepassem em tudo, seria inútil compará-las, uma vez que não restariam pontos de tangência. A partir disso, definiremos o objetivo principal deste trabalho - pretendemos comparar os conceitos de autonomia conforme se apresentam em dois textos específicos: O nacionalismo na atualidade brasileira, publicado por Helio Jaguaribe em 1958; e La política exterior argentina: incongruencia epidérmica y coherencia estructural, escrito por Juan Carlos Puig em 1982. Partimos do pressuposto, entretanto, de que entidades não são comparáveis no vácuo. Em outros termos, será preciso, inicialmente, submeter textos a contextos, de modo que se evite a todo custo reificar conceitos, ou tomar postulados teóricos por construções desinteressadas.

Na primeira seção, situaremos o ambiente histórico específico de cada país - Brasil e Argentina -, bem como as perspectivas de interesse de cada autor ao tempo da publicação de seus textos respectivos. Nas seções seguintes, passaremos à comparação intertextual - de semelhanças a diferenças -, por meio de três variáveis: (1) as táticas textuais - contraste e analogia, onde constataremos similitudes; (2) as prescrições de implementação - no que tange à Terceira Posição e à integração latino-americana - e (3) a tese da (in) constância da política exterior, 
onde constataremos distinções. Reflexamente, compararemos o que se pode chamar de estilística de política exterior. Vale dizer, das diferenças de teoria - presentes nos textos de Jaguaribe e Puig - tentaremos depreender certas diferenças nos padrões de comportamento internacional que têm caracterizado Brasil e Argentina desde a década de 1950 .

\section{Os contextos}

O texto de Helio Jaguaribe foi publicado em 1958 - uma época de esperanças. No Brasil, a estratégia de Kubitschek era dotar suas iniciativas de governo de um apelo ao nacionalismo. Assim, seria destino do país tomar o caminho do desenvolvimento, o que deveria ser buscado por meio da industrialização urgente. O presidente prometera "cinquenta anos de progresso em cinco de governo", cuja base foi um extraordinário incremento da produção industrial. Entre 1957 e 1961, a taxa de crescimento real da economia brasileira foi de $7 \%$ ao ano, ao passo que seu índice per capita para a década de 1950 foi aproximadamente três vezes maior do que o do resto da América Latina. Em seu Plano de Metas, Kubitschek logrou atingir uma nova fase no processo de substituição de importações através de uma política de nacionalismo desenvolvimentista, a qual atuou em três frentes principais: (1) ofereceu ao investidor privado, tanto nacional como estrangeiro, a liberalização do crédito e a promessa de manter um alto nível de demanda interna; (2) incentivou as firmas estrangeiras com o uso abrangente da Instrução 113 da SUMOC, o que rendeu frutos, sobretudo, na indústria automobilística; e (3) empreendeu um amplo programa de investimentos públicos destinado a superar os gargalos estruturais do país em transportes e energia (SKIDMORE, 1982, p. 204-207).

Tal atmosfera de nacionalismo esperançoso não se devia, contudo, apenas às altas taxas de crescimento industrial registradas em fins da década de 1950 . Como pontua Skidmore (1982, p. 207-211), o sucesso da política econômica de Kubitschek foi resultado direto de sua capacidade de manter a estabilidade política. Sua principal arma era o entusiasmo, o que refletia uma confiança contagiante no futuro do Brasil como grande potência, assim como afirmava sua fé no processo democrático. Em seu governo, Kubitschek teve a habilidade de encontrar "uma coisa a cada um", sendo capaz de galvanizar distintos setores sociais em torno do símbolo máximo de seu projeto de superação do atraso - Brasília, a nova 
capital. Dos industriais, teve amplo apoio centrado em sua generosa política de crédito; dos agricultores, teve amparo para suas tentativas de sustentar os preços internacionais do café, bem como para sua indiferença face ao problema da concentração fundiária; à classe trabalhadora, ofereceu aumentos salariais, assim como manteve o controle da estrutura sindical que fora herdada do getulismo. De sua parte, os setores golpistas das Forças Armadas estavam desarticulados desde o bem-sucedido "golpe preventivo" de Lott, o qual havia garantido a posse de Kubitschek à presidência em 1956.

Ao mesmo tempo, muitos intelectuais de ideias nacionalistas foram atraídos pelo entusiasmo de Kubitschek no futuro do Brasil e por sua vontade de acelerar o processo de desenvolvimento. Havia um instituto financiado pelo governo federal - o Instituto Superior de Estudos Brasileiros, ISEB - que se tornou a meca da pesquisa e do ensino dos problemas brasileiros. O instituto publicou uma série de estudos - entre os quais, O nacionalismo na atualidade brasileira, de Helio Jaguaribe - que buscaram racionalizar o problema da industrialização, explicar as causas do subdesenvolvimento e apontar novos caminhos em política exterior. Instituído em 1955, ainda durante o governo de Café Filho, sob os auspícios diretos do Ministério da Educação, o ISEB teve importância central no debate de ideias e de projetos de modernização no Brasil, provendo os alicerces para a teorização do desenvolvimento nacional. Sustentado pelo próprio Estado, o instituto voltou-se para a construção de uma nova legitimidade, colocando-se a serviço da criação de uma síntese do nacional-desenvolvimentismo. Isebiano histórico, Jaguaribe entendia que o nacionalismo teria um caráter mobilizador e aglutinador dos setores progressistas da sociedade, bem como viés autonomizante em relação aos constrangimentos externos do país (LESSA, 2013, p. 883-889).

Segundo Penna Filho (2002, p. 191-194), a política externa brasileira dos anos 1956-1961 executou-se em conformidade com os planos de industrialização do país, sendo possível confrontá-la progressivamente com os avanços logrados pelo Plano de Metas e em função dele. A ação externa de Kubitschek visava ao desenvolvimento por meio de dois eixos cruciais: (1) a obtenção de financiamento e tecnologia dos países avançados do Norte; (2) a manutenção do preço internacional do café, o qual era, até 1957, o principal responsável pela entrada de divisas no comércio exterior do Brasil. Em fins da década de 1950, havia duas perspectivas distintas a respeito da natureza das relações interamericanas. Para os Estados Unidos, importava prioritariamente a agenda de segurança, consubstanciada na doutrina de contenção ao comunismo; para os países da América Latina, a preocupação 
primordial era o desenvolvimento, o que encerrava a necessidade de se debater a industrialização e temas centrais a suas economias, como a deterioração dos termos de troca, a abertura de financiamento externo à indústria, a criação de um banco interamericano para o desenvolvimento e o estabelecimento de processos de integração latino-americana.

Em 1958, Kubitschek lançou a Operação Pan-Americana (OPA), sua mais conhecida iniciativa de política externa, por intermédio de carta enviada ao general Eisenhower, presidente dos Estados Unidos. O que se propunha era que o governo norte-americano se dispusesse a contemplar o pleito dos países latino-americanos por auxílio econômico e maior cooperação para superar o subdesenvolvimento. Apoiando-se no discurso ideológico que opunha "mundo ocidental" a comunismo, Kubitschek afirmava que a ameaça comunista que pairava sobre a América Latina tinha como raiz principal o estado de miséria e subdesenvolvimento da maioria dos países da região. Por meio do argumento da "segurança econômica coletiva", assim, buscava convencer o governo norte-americano de que a melhor forma de se afastar o perigo soviético era desenvolver o continente e aumentar o nível de vida de seus habitantes. Embora tenha tido suas expectativas imediatas reduzidas a muito pouco, a OPA serviria de inspiração à Aliança para o Progresso, a qual surgiria no cenário posterior à Revolução Cubana. No entendimento de Penna Filho (2002, p. 201), é no governo de Kubitschek que a posição do Brasil começa a se alterar com relação à política de blocos da Guerra Fria, o que seria aprofundado com o anúncio da Política Externa Independente (PEI) anos depois.

Por sua vez, o texto de Juan Carlos Puig foi escrito em 1982 - uma época de desilusões. Na Argentina, o retorno de Perón ao poder, em 1973 - em cujo governo Puig fora chanceler -, coincidiu com o fim do sistema Bretton Woods e com o primeiro choque do petróleo, em um cenário de reinvindicações no mundo periférico. Estimulado pelos êxitos da OPEP no âmbito da cooperação Sul-Sul, Perón procurou retomar suas formulações terceiristas da década de 1950, as quais rechaçavam opções de alinhamento com os blocos da Guerra Fria. Em seu natimorto Plano Trienal (1973-1976), enfatizava a abertura de novos mercados e a expansão das exportações industriais. Depois do falecimento de Perón, no entanto, o regime militar daria curso a opções opostas. Em que pese o importante vínculo comercial mantido com a União Soviética para a venda de cereais, os militares argentinos buscaram alinhar-se com os Estados Unidos, respaldando, sobretudo, sua política de intervenção e de combate ao comunismo na América Central. De sua parte, a gestão econômica de Martínez de Hoz encetou enorme abertura às importações 
e verdadeira reprimarização da estrutura produtiva argentina (PARADISO, 2005, p. 247-252).

Ao mesmo tempo, a década de 1970 testemunhou um ambiente de euforia especulativa, no qual muitos países latino-americanos puderam tomar empréstimos com relativa facilidade junto a bancos privados internacionais. Entre 1973 e 1982 , a dívida externa da Argentina aumentou 800\% (FERRER, 2006, p. 239-241). Quando da publicação de La política exterior argentina: incongruencia epidérmica y coherencia estructural, em 1982, o país já sofria os efeitos desastrosos da crise da dívida, a qual havia sido recém detonada como efeito da duplicação das taxas de juros nos Estados Unidos. As desilusões, no entanto, não se deviam apenas ao fracasso das opções de política econômica. No começo da década de 1980, Galtieri buscou recuperar para a Argentina sua longamente perdida posição de país-chave na região, por meio do apoio ostensivo à repressão norte-americana aos sandinistas na Nicarágua. Com base no Tratado Interamericano de Assistência Recíproca (TIAR) e na defesa da segurança hemisférica, a ditadura militar argentina esperava receber em retorno o suporte dos Estados Unidos em sua invasão às Ilhas Malvinas, em 1982. Em razão de seus laços via OTAN com a Europa Ocidental, houve em revés apoio ao Reino Unido, o qual impôs derrota humilhante aos ocupantes (MONIZ BANDEIRA, 2003, p. 444-450).

Em seus textos, Helio Jaguaribe e Juan Carlos Puig desenvolvem suas teorias de autonomia como ferramentas conceituais, tendo-se em vista suas próprias agendas normativas e seus contextos específicos. Assim, Jaguaribe diretor do Departamento de Ciência Política do ISEB em 1958 - busca respaldar o nacionalismo integrador então em curso no governo Kubitschek, bem como defender com veemência um direcionamento autônomo em política exterior, o qual perpassa certo entendimento da "terceira posição" e da função para o Brasil da integração com os vizinhos. De sua parte, Puig - ex-chanceler em 1973 - lamenta os descaminhos da política exterior argentina entre a queda e o retorno de Perón. Na década de 1980, período em que o país começava a redemocratizar-se, Puig volta-se para a defesa do retorno ao caminho autônomo percorrido no primeiro peronismo, abortado no segundo. Nesse passo, seriam igualmente importantes o resgate da "terceira posição" - originalmente formulada por Perón -, assim como da integração latino-americana. Desse modo, o texto de Jaguaribe é prospectivo; o de Puig, retrospectivo. 


\section{Os textos: semelhanças}

Consideramos que, em ambos os casos, os autores empregam táticas textuais semelhantes. Em primeiro lugar, tem-se a que se poderia denominar convencimento por contraste. Por meio de análises histórico-conceituais, Jaguaribe e Puig defendem para seus países o caminho da autonomia em contraste à dependência enraizada no passado colonial, a qual almejam que se abandone. No caso do Brasil, o passivo da escravidão e os efeitos decorrentes da heteronomia e da exogenia econômicas impediram que o país tivesse, até o final do século XIX, condições e estímulos para maior integração que o fizessem voltar-se para si mesmo. A partir da década de 1930, no entanto, eclodiram o nacionalismo econômico - sobretudo, na forma de monopólios estatais - e o nacionalismo político, identificado com as exigências de democracia e de justiça social. Em Jaguaribe, portanto, o conceito de autonomia é indissociável da ideia de nacionalismo integrador. No âmbito interno, a autonomia exige a prevalência da soberania popular; no externo, uma postura de neutralismo:

No plano de nossas relações internacionais, o nacionalismo político reivindica para o país uma posição de maior autonomia, em face dos Estados Unidos e das grandes potências europeias e se inclina para uma linha neutralista, em relação ao conflito norte-americano-soviético. Exprime pois uma tomada de consciência dos interesses próprios do Brasil, no âmbito de outras nações, e das massas populares, no âmbito interno do país, e constitui uma exigência de acatamento da soberania popular e da nacional. (JAGUARIBE, 1958, p. 32)

O texto de Jaguaribe estrutura-se em torno do contraste entre nacionalistas e cosmopolitas. Em sua formulação (p. 33-35), o cosmopolitismo tem três eixos centrais: (1) aspira manter a importância que o livre-cambismo e o setor primário da economia detinham no Império e na República Velha; (2) entende que o progresso nacional depende essencialmente do capital estrangeiro e favorece uma política neocolonialista voltada aos Estados Unidos; (3) engloba segmentos de nível cultural médio, tais como a burguesia latifundiário-mercantil e o setor parasitário da classe média subvencionado pelo Estado cartorial na forma de empregos públicos. Por sua vez, o nacionalismo apresenta seus três contrapontos: (1) aspira ao desenvolvimento do país por meio de um dirigismo racional que favoreça a industrialização via medidas protecionistas e de transferência de renda; (2) inclina-se 
para uma política de capitalismo de Estado, atribuindo ao poder público, em especial na órbita da União, o principal encargo de promover o desenvolvimento econômico do país; (3) engloba os segmentos mais elementares e aqueles dos mais elaborados níveis de cultura e mentalidade, tais como, respectivamente, o proletariado e a intelligentsia da classe média.

Em sua análise histórica da política exterior do Brasil, Jaguaribe (p. 225-232) discerne três fases distintas: (1) da Colônia ao Barão do Rio Branco - cujo propósito é a consolidação da integridade territorial do país; (2) a fase que se estende de 1914 a 1945 - na qual a diplomacia brasileira é conduzida a uma atitude ornamental e aristocrática, quando se avolumam os vínculos de dependência dos Estados Unidos, e a política exterior desvincula-se do processo econômico-social interno; (3) o período posterior a 1945 - quando aparecem as contradições do antigo sentido ornamental em face do novo cenário de hegemonia norte-americana e das novas necessidades do país. Nessa encruzilhada, debatem-se cosmopolitas adeptos da manutenção do americanismo - e nacionalistas, os quais defendem que se adote uma política exterior autônoma e neutralista. Ao ignorar, por exemplo, as especificidades da política exterior da Era Vargas, Jaguaribe posiciona a si mesmo - bem como o governo Kubitschek que o mantém - como arauto de um rompimento, no limiar de um devir.

Na esteira das mudanças sistêmicas ocorridas na década de 1970, o texto de Puig (1982, p. 29-46) não parte da vinculação entre autonomia e nacionalismo, senão da necessidade de se formular uma teoria endógena à América Latina que abandone categorias analíticas embasadas nas realidades distintas dos países centrais. Em uma curiosa aproximação à teoria crítica, Puig enumera três falsas percepções do sistema internacional que se precisaria contornar: (1) a concepção atomista, segundo a qual a comunidade internacional é um conjunto de Estados soberanos que mantêm relações entre si; (2) a de que o poder baseia-se na força material de elementos tangíveis como a preparação militar, a capacidade industrial e o tamanho da população; (3) e a de que o predomínio das superpotências da Guerra Fria é absoluto. Em sua visão, uma teoria que contemple novos recursos de poder a pequenos e médios países deve partir da autonomia - e não da dependência - como valor prescritivo:

Autonomizar significa ampliar a margem de decisão própria e, normalmente, implica portanto recortar a margem de que desfruta algum outro. Salvo casos-limite ou atípicos, a obtenção de uma maior autonomia supõe um jogo 
estratégico prévio de soma-zero, no qual alguém ganha o que outro perde. Avança o antigo cliente; retrocede o antigo dominante. Por mais esforços retóricos que se efetuem, toda abordagem autonomista supõe um conteúdo estratégico, no sentido que implica uma dialética de vontades que empregam a força (em sentido amplo) para resolver o conflito. (PUIG, 1982, p. 44, grifos nossos, tradução livre) ${ }^{2}$

Como pontua Bernal-Meza (2013, p. 49), a teoria de autonomia de Puig é uma visão "realista" das relações internacionais, pois recorre à ideia de disputa de poder mundial ao empregar o “jogo de soma zero" como categoria analítica. Desde o ponto de vista da periferia, Puig busca fornecer um caminho possível para o processo de autonomização a um país cujas elites assumam o encargo de superar a dependência. Assim, emergem dois resultados teóricos inusitados: (1) a crítica voltada às teorias dos países centrais não consegue desvencilhar-se do realismo em sua base fundamental - a disputa de poder; (2) a utilização da lógica do “jogo de soma zero” em nome dos países periféricos da América Latina - e de suas agendas de autonomização - não funciona, a menos que se amplie o sentido de "força” para englobar - provavelmente - valores e intenções.

Publicado no contexto bipolar da segunda Guerra Fria, o texto de Puig (p. 71-87) propõe quatro etapas para o processo de autonomização de um país dentro de um bloco. Desse modo, fornece aos países periféricos um roteiro progressivo para que rompam suas relações de dependência vis-à-vis sua respectiva potência dominante: (1) no nível de dependência paracolonial, o Estado possui um governo formalmente soberano e não é uma colônia, porém em realidade os grupos que detêm o poder efetivo na sociedade nacional constituem um apêndice do aparato governativo e da estrutura de poder do Estado central; (2) no de dependência nacional, os grupos que detêm internamente o poder real racionalizam a dependência e fixam finalidades próprias que podem chegar a conformar um "projeto nacional”; (3) no de autonomia heterodoxa, o Estado periférico continua aceitando a condução estratégica da potência dominante, contudo, seu modelo de desenvolvimento interno poderá chocar-se com os interesses da “metrópole”, bem como pode vir a discordar de medidas de interesse nacional do centro que

2 “Autonomizar significa ampliar el margen de decisión propia y, normalmente, implica por tanto recortar el margen de que disfruta algún otro. Salvo casos-límite o atípicos, el logro de una mayor autonomía supone un juego estratégico previo de suma-cero, en el cual alguien gana lo que otro pierde. Avanza el antiguo cliente; retrocede el antiguo dominante. Por más esfuerzos retóricos que se efectúen, todo planteamiento autonómico supone un contenido estratégico, en el sentido que implica una dialéctica de voluntades que emplean la fuerza (en sentido amplio) para resolver el conflicto.” (PUIG, 1982, p. 44, grifos nossos) 
não coincidam com os interesses do bloco como um todo; (4) no nível final de autonomia secessionista, o Estado rompe o laço estratégico global que o unia à potência dominante e retira-se do bloco.

Tendo por igual objetivo contrastar autonomia e dependência, Puig detecta dois grandes projetos coerentes de política exterior no percurso histórico argentino. Por um lado, o modelo alberdiano da Geração de 80 (p. 93-124) - o qual vigora bem até 1914 - girou em torno da dependência nacional à esfera de influência britânica. No âmbito político, tratava-se de um esforço para tentar limitar o influxo da potência dominante. Em 1902, por exemplo, a Doutrina Drago buscou controlar a utilização da força para a cobrança de obrigações de países periféricos em estado de insolvência. Por outro lado, o texto de Puig (p. 133-141) sustenta a Terceira Posição de Perón (1945-1955; 1973-1976) como um modelo adequado ao contexto posterior à segunda Guerra Mundial, onde o mimetismo eurocêntrico dos anos de 1930 e o isolamento em relação à América Latina não teriam mais lugar. Situada na etapa de autonomia heterodoxa, a política exterior de Perón soube distinguir entre interesses estratégicos do bloco ocidental - quando apoiou a criação do TIAR, por exemplo - e interesses nacionais dos Estados Unidos - ao opor-se à intervenção norte-americana na Guatemala em 1954.

Pensamos que os textos de Jaguaribe e de Puig compartilham uma segunda tática textual, que chamaremos de convencimento por analogia. Em Jaguaribe, o uso da analogia serve para apoiar a tese do neutralismo em política exterior. Na sua concepção, para países como o Brasil, os quais ainda não se encontram na fase de pleno desenvolvimento econômico, o neutralismo é a posição ideológica mais autêntica e representativa, pois acentua o direito à autodeterminação dos povos e à solidariedade internacional em favor do desenvolvimento das comunidades atrasadas, bem como rechaça o imperialismo, o colonialismo e as soluções pela força. Nesse passo, assoma a força de comparação com os Estados Unidos, os quais mantiveram - ao menos até a Primeira Guerra Mundial - postura de neutralidade e de isolamento em relação aos conflitos europeus, assim como a reivindicação de não interferência das potências europeias nos negócios internos da América do Norte:

O princípio da neutralidade exprimia as necessidades de um país em formação, que nada tinha a lucrar com sua participação nos conflitos internacionais, por isso que seus problemas eram internos e sua capacidade de interferência exterior muito limitada, e que muito tinha a perder com os desgastes que tal interferência lhe poderia acarretar e com a contrapartida 
da intervenção estrangeira em seus negócios domésticos [...] São os próprios Estados Unidos, portanto, que demonstram, pelas teses que sustentavam em seu período de formação e pelo acerto pragmático de tais teses, que os países subdesenvolvidos a rigor só podem sustentar o princípio da neutralidade, diante dos conflitos que ultrapassam sua capacidade de interferência e decorrem de interesses que não lhe sejam específicos. (JAGUARIBE, 1958, p. 249-250)

De sua parte, Puig (p. 79-84) vai ainda mais longe em sua utilização da analogia. Em contexto posterior à defecção cubana, o autor busca evidenciar que o percurso histórico norte-americano é exemplo de autonomia secessionista. Em seu enfoque, salienta o exitoso desafio dos Estados Unidos à hegemonia britânica em fins do século XIX, por meio do qual obtiveram reconhecimento formal de sua supremacia na América Central e no Caribe. Parece-nos que o texto de Puig avança algo como um argumento a fortiori, ou um enunciado que diz: se os Estados Unidos - a partir da década de 1950, superpotência empenhada em tolher o processo de autonomização dos países latino-americanos em nome da contenção ao comunismo - fizeram alguma vez uso de uma postura de política exterior desafiante e de secessão, com razões suficientes poderá então a Argentina - despida de ferramentas conceituais destinadas a manter e mascarar sua condição de dependência - fazer o menos, isto é, resgatar e aprofundar sua posição internacional de autonomia heterodoxa, o terceirismo.

\section{Os textos: diferenças}

Embora os dois textos apresentem agendas semelhantes e utilizem táticas de convencimento paralelas, parece-nos importante ressaltar diferenças conceituais que resultam em distintas prescrições de implementação. Central ao raciocínio de Puig (1982, p. 41) é o conceito de Terceira Posição. Em seu primeiro governo, Perón foi pioneiro ao demonstrar que a opção pela autonomia era factível mesmo para um país periférico, desde que se pudesse ter controle interno sobre determinadas variáveis econômicas - tais como o comércio exterior, o investimento estrangeiro, o crédito e o câmbio - e fosse possível manter-se à margem das diretivas do Fundo Monetário Internacional. Externamente, a Terceira Posição somente poderia sustentar-se por meio de uma política de alianças entre os países dependentes. O conceito encerraria, assim, duas facetas: 
Desde o ponto de vista interno, significava uma alternativa distinta, à michemin entre o individualismo capitalista e o socialismo coletivista. Como tal, era e segue sendo válida: sem ir mais longe é o que postula a Igreja Católica em sua doutrina social. Em relação ao âmbito externo, significava a "não alienação” e nesse sentido há que se reconhecer que Perón foi o precursor do atual Movimento dos Não Alinhados. (PUIG, 1982, p. 137, tradução livre) ${ }^{3}$

É preciso discernir a motivação de Puig, o qual escreve no início da década de 1980 com o fito de defender o retorno da autonomia heterodoxa - e da Terceira Posição -, que não havia podido implementar por completo quando chanceler em 1973. Em seu contexto, o postulado teórico da "frente dos povos atrasados" serviria de base para se analisar a possibilidade estratégica de um cartel de devedores (p. 67), posição que a Argentina sustentaria como alternativa viável ao cenário desastroso advindo da crise da dívida. Por sua vez, desde que Jaguaribe enunciou seu próprio entendimento da Terceira Posição em fins da década de 1950, o Brasil passaria a ver com mais prudência o "espírito de Bandung” em seu ativismo obstrucionista.

Em um provável rebate a Perón, o texto de Jaguaribe (1958, p. 259-265) parte da premissa de que não mais haveria em seu tempo um confronto ideológico real entre "individualismo capitalista" e "socialismo coletivista", pois seus formatos puros originais do século XIX não mais persistiriam. Desse modo, não haveria duas culturas - norte-americana e soviética - em conflito, mas apenas uma cultura, a da civilização ocidental-universal. Disso decorre um corolário conceitual aos países em vias de desenvolvimento: do ponto de vista ideológico, não se poderia falar de uma "terceira posição" que seria tal em face de uma "primeira posição" - norte-americano-capitalista - e de uma "segunda posição" - soviético-socialista. Assim, a Terceira Posição não poderia ser considerada uma superação ou um meio caminho entre os dois modelos, uma vez que as estruturas produtivas efetivas do capitalismo e do socialismo já se encontrariam nos anos de 1950 suficientemente próximas para elidir uma clivagem absoluta. Além disso, a Terceira Posição tampouco poderia ser identificada com uma "terceira força”, visto que nenhum país ou grupo de países teria condições de fazer frente a quaisquer das superpotências sem que houvesse o concurso de uma delas.

3 "Desde el punto de vista interno, significaba una alternativa distinta, à mi-chemin entre el individualismo capitalista y el socialismo colectivista. Como tal, era y sigue siendo válida: sin ir más lejos es lo que postula la Iglesia Católica en su doctrina social. En cuanto a lo externo, significaba la "no alienación” y en este sentido hay que reconocer que Perón fue el precursor del actual Movimiento de los No Alienados.” (PUIG, 1982, p. 137) 
Dessa forma, é possível afirmar que Jaguaribe rechaça a Terceira Posição de Perón inteiramente, em suas duas facetas: (1) no âmbito interno, o terceirismo não poderia significar alternativa ou mi-chemin original entre o capitalismo e o socialismo, uma vez que os dois sistemas já se encontravam de todo modo em um processo global de aproximação - em que o Estado de bem-estar social emergia como fenômeno exemplar nos próprios países centrais; (2) no âmbito externo, o terceirismo não poderia significar algo como uma "frente dos povos atrasados" tal como se definiria abertamente o Movimento dos Não Alinhados -, visto que em sua formulação a "força" - seja em sentido amplo ou estrito - não encontra lugar. Em seu texto, a Terceira Posição tem um conteúdo conceitual positivo bastante diverso, qual seja, a parlamentarização do conflito norte-americano-soviético:

A terceira posição é uma ideologia que se afirma em face do conflito norte-americano-soviético, tal como este empiricamente se desenrola [...] [Há] duas posições que se defrontam, em nosso tempo, em função da alternativa do mundo contemporâneo: a da unificação político-jurídica do mundo pela constituição de um novo império mundial, independentemente do fato de centrar-se tal império nos Estados Unidos ou na União Soviética, e a unificação do mundo mediante o gradual consenso, e a parlamentarização do conflito norte-americano-soviético [...] O imperialismo mundial só pode ser evitado se os atuais antagonismos forem ajustados transacionalmente, pela mediação arbitral dos neutros. O que a terceira posição tem em vista e o que constitui sua razão de ser é a instauração dessa instância mundial de arbitramento e o fortalecimento das castas que conduzem à composição transacional dos interesses. (JAGUARIBE, 1958, p. 261-262, grifos nossos)

Em Jaguaribe, portanto, terceirismo não tem nada que ver com "terceira via" entre os modelos de estrutura produtiva existentes, capitalismo e socialismo, nem com "terceira força" ou frente dos países atrasados que almeje medir forças com os dois blocos da Guerra Fria. Seu terceirismo remete, antes disso, ao terceiro mediador. Na sua concepção, os países periféricos aptos a adotar a Terceira Posição - entre os quais, o Brasil - não funcionariam como "forças" interessadas, senão como promotores neutros da diplomacia parlamentar e de soluções concertadas. Parece-nos importante relacionar tais discrepâncias conceituais com os distintos estilos de política exterior de ambos os países. No caso argentino, o terceirismo de Perón e a adesão ao Movimento dos Não Alinhados revelam tendência maior ao rompimento e a saídas de extremo; no caso do Brasil, o terceirismo da PEI e a circunspecção com a qual se veria o "espírito de Bandung" sinalizam apreço maior ao meio-termo e à acomodação. 
Pensamos também ser relevante salientar que os textos apresentam nuances de importância e distinções de conceito no que atine à integração latino-americana. Em Jaguaribe (p. 54-55), o nacionalismo é entendido como um processo dialético e dinâmico de transformações históricas. No curto prazo, o nacionalismo brasileiro deveria realizar-se mediante a transformação das estruturas tradicionais internas. Em nova analogia, o autor destaca que os países europeus eram mais nacionalistas no século XIX, visto que ainda estavam em vias de esgotamento das possibilidades de desenvolvimento no quadro estreito de suas próprias nacionalidades. Uma vez que se ultrapassou tal etapa, fez-se vital a necessidade de constituir uma unidade mais ampla na Europa que fosse dotada de instituições supranacionais - de que a CECA foi o primeiro exemplo em 1951. No caso do Brasil, ainda às voltas com o imperativo de um nacionalismo integrador, a integração da América Latina como bem evidenciaria o malogro posterior da ALALC - não poderia emergir, portanto, como panaceia aos males, senão como processo de longo prazo, que ainda seria prematuro conceber.

Em sua visão (p. 278-280), a integração latino-americana não apenas submete-se ao nacionalismo, mas também possui um conteúdo semântico específico e um alcance imediato reduzido. Sua principal função é política - a união da América Latina serviria para obter ao Brasil apoio externo à sua postura internacional de neutralismo e anular o poder de represália dos Estados Unidos. Não poderia haver integração do subcontinente sem que primeiro se partisse de uma “estreita e operante vinculação entre o Brasil e a Argentina”, cuja concertação de diretrizes de atuação internacional constituiria um "imperativo estratégico elementar para ambos os países” - de que o “espírito de Uruguaiana” seria em Kubitschek o ensaio inicial. Por outro lado, a agenda de integração econômica da América Latina - com base em um mercado comum - é vista pelo autor com maior parcimônia, pois deveria estar sujeita à "regulamentação acautelada dos interesses de cada parte”.

Conforme frisa Bernal-Meza (2013, p. 51-54), Puig considera que a autonomia pode ser atingida por meio da integração latino-americana, de modo que em sua teoria o nacionalismo não emerge como elemento de maior importância. Assim, os distintos níveis de desenvolvimento dos países da América Latina - fator que poderia vir a enfraquecer o projeto de integração - deveriam ser amenizados pela solidariedade. Uma integração solidária seria uma alternativa à mera integração de interdependência econômico-comercial. Seu núcleo comum - onde se detecta talvez alguma influência da Escola Inglesa - seria o compartilhamento de valores 
comuns, sobretudo, a própria agenda de autonomia. Em seu texto, Puig (p. 115; p. 138-139) destaca o contraste que os dois projetos nacionais coerentes de política exterior argentina - o da Geração de 80 e o da Terceira Posição - apresentaram no quesito da integração latino-americana. Uma das linhas-força do primeiro foi rechaçar quaisquer ensaios bolivarianistas de associação permanente. Em Perón, entretanto, ocorreu uma reviravolta fundamental. O tradicional isolamento foi transformado em seu reverso, de modo que se tentou implementar uma união econômica entre Argentina, Paraguai, Equador, Chile, Bolívia e Nicarágua - e mesmo reformular o Pacto ABC.

Parece-nos que as distintas nuances de importância que recebe a integração da América Latina em ambos os textos também podem revelar linhas discrepantes dos estilos de política exterior de Brasil e Argentina. Assim, o Brasil - maior país e líder natural da América do Sul já na década de 1950 - tenderia a suspeitar de projetos de engajamento demasiado abrangentes, em especial daqueles que o pudessem nivelar com seus vizinhos menores por meio do funcionamento de instituições supranacionais. É sabido que a ALALC apenas daria lugar à nova “divisão centro-periferia”, porém, em escala menor, onde o Brasil emergiria como potência industrial. Assim, em Jaguaribe, sua agenda prioritária é minimalista: o que se deve garantir é o eixo estratégico Brasil-Argentina. De sua parte, à Argentina, que desde a década de 1930 iniciara sua rota de decadência relativa na região, seria mais interessante - em que pese sua diplomacia de idas e vindas - promover um cenário de integração holístico e mais ambicioso, onde pudesse, talvez, emergir como líder de seus inúmeros vizinhos de fala espanhola.

\section{Política exterior: ruptura e continuidade}

A partir dos contextos e das táticas textuais salientadas nas seções anteriores, podemos retornar a um ponto central de nossa análise comparativa: a detecção das estratégias globais de ambos os textos, as quais estão ligadas às agendas políticas respectivas de cada autor. Mais precisamente, será possível articular tais interesses ao modo como cada um posiciona-se a respeito do debate - de resto, um bizantinismo vazio - sobre a (in)constância das políticas exteriores de Brasil e Argentina. No que se refere a Puig, é clara sua motivação de fundo: uma vez encerrado o regime militar, defender no começo da década de 1980 o retorno ao terceirismo de Perón, linha diplomática que havia ajudado a implementar quando chanceler em 1973: 
Em suas grandes linhas, a política exterior inaugurada em 1946, descontinuada arbitrariamente em 1955, retomada em 1973 e também depois esvaziada de conteúdo, deve ser "a" política exterior argentina, adaptada a mudanças adicionais e ainda dialéticas que se produzam no regime internacional. É lisonjeiro ao autor deste livro, chanceler em 1973, comprovar que ao cabo de nove anos, apesar de críticas no mais das vezes emocionais e de inflamadas perseguições ocultas e ostensivas, é demonstrado que estava correto quanto contribuiu a planejar e executar a única ação externa que é funcional à realidade social e geopolítica argentina e à estrutura e funcionamento do regime internacional atual. (PUIG, 1982, p. 163, grifos nossos, tradução livre) ${ }^{4}$

É preciso compreender que a teoria de autonomia de Puig prevê um processo de autonomização, vale dizer, um percurso gradual por etapas que, no exemplo histórico argentino, foi da dependência nacional da Geração de 80 à autonomia heterodoxa do terceirismo. Assim, muito embora o autor contraste as opções de cada período, não nos parece que advogue uma ruptura total com o passado. O objetivo teórico primordial de seu texto é evidenciar a coerência estrutural da política exterior argentina por meio do delineamento de suas tendências profundas. Nesse sentido, Puig (1982, p. 102) salienta quatro constantes inauguradas no modelo alberdiano, que se encerra em 1914: (1) afiliação à esfera de influência britânica; (2) indiferença, isolamento e oposição aos Estados Unidos; (3) isolamento com respeito à América Latina; e (4) debilidade da política territorial.

Tendo em mente sua defesa do terceirismo, é importante destacar a relação estabelecida entre a segunda e a quarta constantes da política exterior argentina, com notada ênfase no caso das Malvinas. Como afirma Puig (1982, p. 111-112), o afastamento em relação aos Estados Unidos - bastante marcado no período da Geração de 80 - radicou-se em sua congruência com o projeto nacional da República Argentina. Por um lado, isso deveu-se à afiliação à Inglaterra e ao baixo intercâmbio comercial com os norte-americanos. Por outro, decorreu do episódio das Malvinas. Significativamente, Puig aponta a postura político-diplomática hostil dos Estados Unidos como principal responsável pela perda das ilhas no século XIX. Assim, afirma o autor que somente após a destruição da colônia argentina

4 "En sus grandes rasgos, la política exterior inaugurada en 1946, discontinuada arbitrariamente en 1955, retomada en 1973 y también vaciada de contenido después, debe ser "la" política exterior argentina, adaptada a los cambios incrementales y aun dialécticos que se vayan produciendo en el régimen internacional. Es halagador para el autor de este libro, canciller en 1973, comprobar que al cabo de nueve años, a pesar de críticas las más de las veces emocionales y de enconadas persecuciones solapadas y ostensibles, se demuestra que estuvo acertado cuando contribuyó a planear y ejecutar la única acción externa que es funcional a la realidad social y geopolítica argentina y a la estructura y funcionamiento del régimen internacional actual.” (PUIG, 1982, p. 163, grifos nossos) 
pelo navio de guerra norte-americano Lexington pôde ocorrer a ocupação britânica das Malvinas, o que não foi de modo algum obstaculizado pelos Estados Unidos.

Após o fim da Segunda Guerra Mundial, o terceirismo de Perón emerge como um novo projeto nacional coerente em sua política exterior. Em meio a um regime internacional modificado - onde se destaca a decadência do europeísmo -, mantém-se, contudo, a postura de afastamento em relação aos Estados Unidos. Desse modo, a Argentina optou por não aderir aos acordos de Bretton Woods (1944), que criaram o FMI e o BIRD, bem como colocou-se à parte do multilateralismo comercial pregado pelos países desenvolvidos ocidentais. No que atine à política territorial, Perón voltou-se para a defesa do patrimônio nacional, com o que se retomou a reivindicação pelas ilhas Malvinas e se iniciaram as expedições ao continente antártico com vistas à exploração de recursos naturais (PUIG, 1982, p. 134-140).

As críticas imediatas de Puig voltam-se à esquizofrenia da política exterior do regime militar (1976-1983). Por um lado, os militares argentinos mantiveram algumas pautas típicas da autonomia heterodoxa em relação aos Estados Unidos, tais como nas políticas nuclear e de direitos humanos - em especial na administração Carter - e no rechaço ao embargo comercial à União Soviética, país que recebia 37,5\% das exportações argentinas em 1981. Por outro, sua política econômica dependente - que implicou verdadeiro processo de desindustrialização - e o contexto político repressivo e excludente impediram que a política exterior de orientação autonomista pudesse estruturar-se em um projeto coerente e global (1982, p. 155). Em uma insólita "lua de mel" com Ronald Reagan, Galtieri efetivou de forma irracional a invasão das ilhas Malvinas a partir de uma sobrevalorização equivocada da importância argentina nos assuntos norte-americanos na América Central.

Desse modo, parece-nos que Puig articula a tese da coerência da politica exterior argentina tendo em vista seu objetivo político primordial - a retomada do terceirismo que ajudou a implementar durante o segundo governo Perón: (1) ao identificar somente dois projetos coerentes de política exterior na história argentina - o da Geração de 80 e o próprio terceirismo; (2) ao traçar algumas linhas de continuidade entre ambos, sobretudo no que se refere ao afastamento em relação aos Estados Unidos; (3) ao narrar a perda das Malvinas no século XIX por meio das tintas do conflito de 1982, isto é, ao sublinhar a hostilidade diplomática norteamericana à demanda argentina e sua conivência à (re)ocupação britânica. Por meio de táticas tais de presentismo, Puig amarra a Terceira Posição à necessidade do fluxo histórico e reforça seu argumento para que essa retorne na década de 1980 . 
Por sua vez, em uma sugestiva reflexão sobre a "psicologia do nacionalismo", Jaguaribe (1958, p. 34-36) trai suas motivações políticas. Por um lado, afirma que o nacionalismo é aspiração do setor mais dinâmico da burguesia - empenhado na revolução industrial - e do proletariado - cuja capacidade de consumo se expande com o grau de industrialização. Por outro lado, "são de tendência nacionalista os quadros técnicos e administrativos e a intelligentsia da classe média, vinculados, simultaneamente, ao processo de desenvolvimento e à consolidação interna e externa do Estado”. Uma tomada de consciência crítica privada de sistemas de referência, contudo, conduz o brasileiro médio ao desprezo pelo próprio país e lhe inspira um “cosmopolitismo de compensação”, posturas ligadas aos interesses alienantes da burguesia latifúndio-mercantil e da ampla parcela da classe média subvencionada pelo Estado cartorial. Somente uma "compreensão sociológica e historicamente qualificada da realidade brasileira” poderia suscitar a orientação nacionalista e conduzir à convicção de que o país tem condições para se tornar a curto prazo uma grande nação.

Parece-nos que Jaguaribe, intelectual representante da intelligentsia da classe média, coloca-se na privilegiada posição de quem esclarece. Através da compreensão qualificada da realidade brasileira que seu texto almeja oferecer, poderia o brasileiro médio - ao menos quem pudesse ler - ter acesso a um sistema de referência válido para sua adequada tomada de consciência e adesão à ideologia nacionalista. Parece-nos claro, ademais, que seu texto - publicado em 1958 sob os auspícios do ISEB, órgão vinculado ao Ministério da Educação e Cultura - prima pela defesa e pela formulação conceitual do nacionalismo integrador característico do governo JK, então em curso.

Nesse sentido, também se pode discernir a articulação existente entre sua defesa política do nacionalismo e o modo como maneja a tese da (in)constância da política exterior brasileira. Constata Jaguaribe (1958, p. 221-225) que, desde o final da Segunda Guerra Mundial, tornou-se crescente a percepção da opinião pública brasileira acerca das correlações existentes entre o desenvolvimento econômico-social do país e sua política exterior. A partir disso, não poupa críticas ao que denomina como a "crise do Itamaraty". Em primeiro lugar, o Itamaraty havia perdido a autonomia que desfrutara, durante a República Velha, na elaboração e execução da política exterior brasileira, em virtude da interferência de outros órgãos administrativos - tais como o CSN, o BNDE e a Petrobrás -, da Presidência da República, do Congresso Nacional, da imprensa e de órgãos de classe. Pior do que isso, o Itamaraty mantinha-se adstrito à rotineira aplicação de 
precedentes que quase sempre remontavam à época do Barão do Rio Branco, com o que a diplomacia brasileira permanecia embebida de um sentido ornamental e aristocrático conjugado com a prática de um americanismo anacrônico e de um anticolonialismo e latino-americanismo inoperantes.

É sintomática a maneira como Jaguaribe (1958, p. 225-228) periodiza a história da política exterior brasileira. Em uma primeira fase, que se estende do período colonial à gestão do Barão do Rio Branco, as características comuns são a defesa e a consolidação da integridade territorial do país, sempre orientadas no sentido de um sistema de forças favorável na América do Sul. Na segunda fase, de 1914 a 1945, radica, segundo sua leitura, o período de crise do Itamaraty. Nesse momento, a diplomacia brasileira voltou-se a "proporcionar às elites dirigentes uma participação nos estilos de vida das classes superiores europeias e a apresentar o país em ângulo favorável, valorizando seus ângulos de civilização". Ao mesmo tempo, a aplicação estéril de precedentes e a ostentação de uma mentalidade aristocrático-ornamental levaram os representantes brasileiros no exterior a buscar a simpatia e a adesão de classes dirigentes estrangeiras em detrimento da defesa dos interesses nacionais. Assim, no final da década de 1950, o Itamaraty carecia tanto de representatividade para elaborar e executar a política exterior brasileira, bem como de autenticidade, pois não se encontrava a par das necessidades históricas do país.

Após a guerra, abre-se uma nova fase de nossa política exterior, a qual sinaliza a impossibilidade de perduração de seu antigo sentido ornamental e as contradições que afetam suas formulações. Parece-nos que Jaguaribe é assertivo neste ponto: é preciso romper com a tradição aristocrática que permeou a política exterior brasileira desde o século XIX e que encontrou seu ápice histórico na gestão do Barão do Rio Branco. Se aquele perfil diplomático havia sido exitoso em cerrar as fronteiras do país, não mais serviria para implementar uma agenda nacionalista de integração do próprio território, visto que sempre esteve comprometido com o Estado cartorial. Conforme salientamos acima, o conceito de autonomia em Jaguaribe apresenta dois vetores essenciais: internamente, a soberania popular; externamente, o neutralismo. Em sua visão (1958, p. 271-276), a elaboração e execução de uma política exterior autônoma seriam indissociáveis do desenvolvimento econômico-social do país e de uma revolução nacional-democrática que desmantelasse as estruturas clientelistas e oligárquicas do Estado cartorial, o qual esteve historicamente associado à prática diplomática. Assim, não surpreende sua conclusão de que a autonomia do Brasil não deveria passar pela autonomia do Itamaraty: 
Aplicando à questão em exame os ensinamentos dessas observações, pode-se prognosticar, inicialmente, que a política exterior, por sua estreita vinculação com a segurança nacional, tende a ser submetida a uma elaboração colegiada, relativamente isenta das influências clientelistas e cartoriais. Na medida que, paralelamente, no âmbito do Itamarati, se tornem mais influentes os diplomatas de formação técnica, as circunstâncias tenderão a encaminhar-se no sentido da criação de um Conselho de Política Exterior, que assumirá a policy making de nossa diplomacia. Um Conselho desse gênero, ainda que submetido a regime mais informal, tenderá a refletir a orientação desenvolvimentista que já se tornou predominante nos órgãos citados [BNDE, CACEX e SUMOC] e assim encaminhar nossa política exterior para uma posição de independência e autonomia [...] A partir do momento no qual, em virtude das tendências assinaladas, a política exterior brasileira passe a ser elaborada por uma agência colegiada representativa de nosso processo de desenvolvimento, este, de modo geral, se tornará mais vigoroso e acelerado. (JAGUARIBE, 1958, p. 274-275, grifos nossos)

Compreendido em seus próprios termos, Jaguaribe não pode ser considerado simplesmente como um antecipador da Política Externa Independente (1961), menos ainda como quem somente reconhece e louva a importância do Itamaraty e de suas tradições históricas. Ligado à ideologia nacionalista de seu grupo de interesses - a intelligentsia da classe média -, de nada serviria sustentar a tese da continuidade da política exterior brasileira. Ao contrário, o que Jaguaribe almeja anunciar é uma nova fase em que as práticas diplomáticas possam romper com o padrão acumulado de aristocratismo ornamental e do mimetismo ao Barão do Rio Branco, tão associados a uma concepção elitista e ultrapassada das funções do Estado. Dessa forma, é natural que defenda a criação de um órgão colegiado capaz de reduzir a influência esclerosante do Itamaraty e de formular e executar uma política exterior consonante com o nacionalismo e o neutralismo adequados aos novos tempos.

\section{Conclusões}

No presente trabalho, buscamos comparar os conceitos de autonomia de Helio Jaguaribe e de Juan Carlos Puig a partir de uma pequena análise intertextual. Assim, foi possível constatar que ambos os autores sustentam para seus respectivos países - Brasil e Argentina - agendas de autonomização. Escrevendo no final da 
década de 1950, Jaguaribe percebeu que o já anacrônico americanismo de Rio Branco deveria ceder espaço ao neutralismo, como ferramenta útil de política exterior que pudesse servir aos fins últimos do desenvolvimento e da integração do território nacional. Por detrás disso, ao mesmo tempo, transparece em seu texto seu pertencimento a uma parcela de classe média da intelligentsia aninhada no ISEB que almeja ocupar posições de proa na definição dos rumos do governo de Kubitschek - o que converte seu texto em um instrumento de luta e de afirmação de interesses.

De sua parte, Puig escreve seu texto como arma de defesa do terceirismo. Em sua visão, somente o projeto alberdiano da Geração de 80 - que não poderia mais retornar - e a Terceira Posição de Perón haviam sido capazes de dotar a política exterior argentina - de resto, superficialmente hesitante - de projetos nacionais coerentes. Em princípios da década de 1980, momento em que a Argentina padecia os descaminhos da crise da dívida e do passivo do regime militar, Puig - que tivera sua própria experiência como chanceler abreviada a partir de 1973 - vislumbra o retorno de um tipo de inserção internacional cara a seus interesses e à sua própria visão de mundo. Em que pese a semelhança de suas agendas e mesmo do tom de suas exortações, os dois textos comparados, portanto, tiveram sortes bem distintas. De um contexto de esperanças, Jaguaribe soube extrair poderes de clarividência: com a devida seleção de ênfase, seu texto viria a ser considerado pela diplomacia brasileira como o anúncio de uma nova era. De um contexto de desilusões, Puig não pôde fazer mais do que sustentar o improvável retorno de um peronismo em vias de falecimento. O realismo periférico exibiria o malogro quixotesco de suas previsões.

\section{Referências}

BERNAL-MEZA, Raúl. Heterodox Autonomy Doctrine: realism and purposes, and its relevance. Revista Brasileira de Política Internacional, v. 56, n. 2, 2013, p. 45-62. Disponível em: [http://www.scielo.br/pdf/rbpi/v56n2/v56n2a03.pdf]. Acesso em: 24 fev. 2016.

FERRER, Aldo. A economia argentina: de suas origens ao início do século XXI. Tradução S. Duarte. Rio de Janeiro: Elsevier, 2006.

JAGUARIBE, Helio. O Nacionalismo na Atualidade Brasileira. Rio de Janeiro: Ministério da Educação e Cultura/Instituto Superior de Estudos Brasileiros, 1958. 
LESSA, Antonio Carlos. Helio Jaguaribe: a geração do nacional-desenvolvimentismo. In: PIMENTEL, José Vicente de Sá (organizador). Pensamento diplomático brasileiro: formuladores e agentes da política externa (1750-1964). Brasília: Funag, 2013, Vol. 3, Cap. 7, p. 877-902.

MONIZ BANDEIRA, Luiz Alberto. Brasil, Argentina e Estados Unidos: conflito e integração na América do Sul (da Tríplice Aliança ao Mercosul, 1870-2003). 2a ed. Rio de Janeiro: Revan, 2003.

PARADISO, José. Um lugar no mundo: a Argentina e a busca da identidade internacional. Tradução de Sérgio Bath. Rio de Janeiro: Civilização Brasileira, 2005.

PENNA FILHO, Pio. Política Externa e Desenvolvimento - o Brasil de JK. Cena Internacional, v. 4, n. 1, 2002, p. 189-208.

PUIG, Juan Carlos. La política exterior argentina: incongruencia epidérmica y coherencia estructural. In: PUIG, Juan Carlos (compilador). America Latina: politicas exteriores comparadas. Tomo I. Buenos Aires: Grupo Editor Latinoamericano, 1982, p. 24-163. SARTORI, Giovani. Comparación y Método Comparativo. In: SARTORI, Giovani \& MORLINO, Leonardo. La comparación en las Ciencias Sociales. Madrid: Alianza, 1994, Cap. 2, p. 29-49.

SKIDMORE, Thomas E. Brasil: de Getúlio Vargas a Castelo Branco. Apresentação de Francisco de Assis Barbosa. Tradução coordenada por Ismênia Tunas Dantas. $7^{\text {a }}$ ed. Rio de Janeiro: Paz e Terra, 1982. 